\title{
Assessment of Visual Outcome of Anisometropic Amblyopia after LASIK Treatment
}

\author{
Diar Hadi Saeed ${ }^{1}$, Ali Abdullah Taqi ${ }^{*}$ \\ ${ }^{1}$ MB.Ch.B/D.O, Ophthalmologist, Aso eye hospital, Ministry of health, Kurdistan, Iraq. \\ ${ }^{2}$ MB.Ch.B/D.O/CABM(Ophth), Head of Ophthalmology Unit, University of Sulaimani, Kurdistan, Iraq.
}

\begin{abstract}
Background: Anisometropic amblyopia is characterized by a decrease in best corrected visual acuity in one eye as a result of significantly different refractive errors between the two eyes. Without the presence of ptosis or strabismus as a visible warning sign, these patients may be diagnosed significantly later in life, and unfortunately some go untreated. Newer options have been introduced in the management of anisometropic amblyopia. This study was conducted to evaluate the visual outcome of patients with anisometropic amblyopia after LASIK surgery.

Materials \&Methods: The present prospective study included a total of 70 cases (66 with bilateral treatment and 4 with unilateral treatment) in SOMA centre in Sulaimani done that reported from 2008 to 2009. The SOMA centre is a centre for correcting vision with LASER. Demographic details of the patients along with complete detailed history of the patients with clinical assessment was done with the help of the questionnaire. Visual acuity $E$ chart were used for carrying out visual activity of the patients and the measurement was taken with and without the patient's own glasses. For each case, automated-refraction and subjective refraction were done. The anterior and posterior segments were examined with slit-lamp. After performing the LASIK surgery, follow-up examination was done for all patients at next day, 1 week and 1 month later on.

Results: $51.4 \%$ percent of the patients in the present study were males and $48.6 \%$ were females. Subjects were almost equally distributed to inside and outside Sulaimani city.
\end{abstract}

\section{INTRODUCTION}

Anisometropic amblyopia is characterized by a decrease in best corrected visual acuity in one eye as a result of significantly different refractive errors between the two eyes. The eye that ultimately provides a more blurred image to the visual cortex develops amblyopia. ${ }^{1}$ Several authors have suggested that anisometropia is the leading cause of amblyopia and is responsible for approximately $50 \%$ of all cases. ${ }^{2,3}$ Without the presence of ptosis or strabismus as a visible warning sign, these patients may be diagnosed significantly later in life, and unfortunately some go untreated. 3,4 As the traditional treatment has many problems, a new option was introduced in the management of anisometropic amblyopia, which is laser in-situ keratomileusis (LASIK). ${ }^{5}$ This study was conducted to evaluate the visual outcome of patients with anisometropic amblyopia after LASIK surgery.
Statistically significant result was obtained while comparing the amblyopic and non-amblyopic eye in uncorrected visual acuity. Also on comparing amblyopic and non-amblyopic eye for best corrected visual acuity, statistically significant results were obtained. In patients with uncorrected visual acuity, significant results were obtained while comparing follow-up at all the postsurgical time intervals. Whereas in patients with best corrected visual acuity, significant results were obtained at 1 month follow-up time.

Conclusion: For the treatment of ametropic and anisometropic amblyopia, excimer laser refractive surgery appears to be a safe and efficient procedure.

Key Words: Amblyopia, LASIK, Surgery.

*Correspondence to:

Dr Ali Abdullah Taqi,

Head of Ophthalmology Unit,

University of Sulaimani, Kurdistan, Iraq.

Article History:

Received: 05-06-2016, Revised: 08-06-2016, Accepted: 09-06-2016

\begin{tabular}{|l|c|}
\hline \multicolumn{2}{|c|}{ Access this article online } \\
\hline $\begin{array}{l}\text { Website: } \\
\text { www.ijmrp.com }\end{array}$ & Quick Response code \\
\hline DOI: & \\
10.21276/ijmrp.2016.2.4.033 & \\
\hline
\end{tabular}

\section{MATERIALS \& METHODS}

The present prospective study included a total of $70(51.4 \%$ male and $48.6 \%$ females) cases 66 with bilateral treatment and 4 with unilateral treatment in SOMA centre in Sulaimani done that reported from 2008 to 2009 . The SOMA centre is a centre for correcting vision with LASER. Interviewing of each individual case was done using a specially designed questionnaire which contained systemic and ocular histories with the result of examination. Demographic details of the patients along with complete detailed history of the patients with clinical assessment were done with the help of the questionnaire. For both the eyes, separate and detailed ocular examination was carried out. Slitlamp was used for examination of both the anterior and posterior segments. E chart were used for carrying out visual activity of the patients and the measurement was taken with and without the 
patient's own glasses. For each case, automated-refraction and subjective refraction were done. Keratometry, pachymetry and corneal topography also were done. Examination of the corneas of the patients was done before the surgery with the purpose of determination of thickness of cornea and with a topographer to measure their surface contour. Using low-power lasers, a topographer creates a topographic map of the cornea. This process also detects astigmatism and other irregularities in the shape of the cornea. Using this information, the surgeon calculates the amount and locations of corneal tissue to be removed during the operation. Each case was examined postoperatively. The anterior and posterior segments were examined with slit-lamp, checking visual acuity with Visual acuity E chart. After performing the LASIK surgery, follow-up examination was done immediately, at next day, 1 weeks' time and after 1 month later on.

Table 1: Comparative evaluation of the pre-surgical uncorrected and best corrected visual acuity between the amblyopic and non-amblyopic among the subjects.

\begin{tabular}{llccc}
\hline Visual acuity & & Amblyopic eye & Non-amblyopic eye & p-value \\
\hline Uncorrected & Mean & 0.14 & 0.80 & $0.001^{*}$ \\
& Range & $0.03-0.30$ & $0.5-1.5$ & \\
Best corrected & Mean & 0.40 & 1.0 & $0.001^{*}$ \\
& Range & $0.20-0.65$ & $0.6-1.0$ & \\
\hline
\end{tabular}

*: Significant

Table 2: The uncorrected and best corrected visual acuity before and after operation among the study patients

\begin{tabular}{llccc}
\hline Visual acuity & & Pre-surgical & $\begin{array}{c}1 \text { day } \\
\text { post-surgical }\end{array}$ & $\begin{array}{c}1 \text { month } \\
\text { post-surgical }\end{array}$ \\
\hline Uncorrected & Mean & 0.12 & 0.40 & 0.58 \\
& p-value & - & $0.001^{*}$ & $0.001^{*}$ \\
Best corrected & Mean & 0.40 & 0.40 & 0.57 \\
& p-value & - & 0.211 & $0.001^{*}$ \\
\hline
\end{tabular}

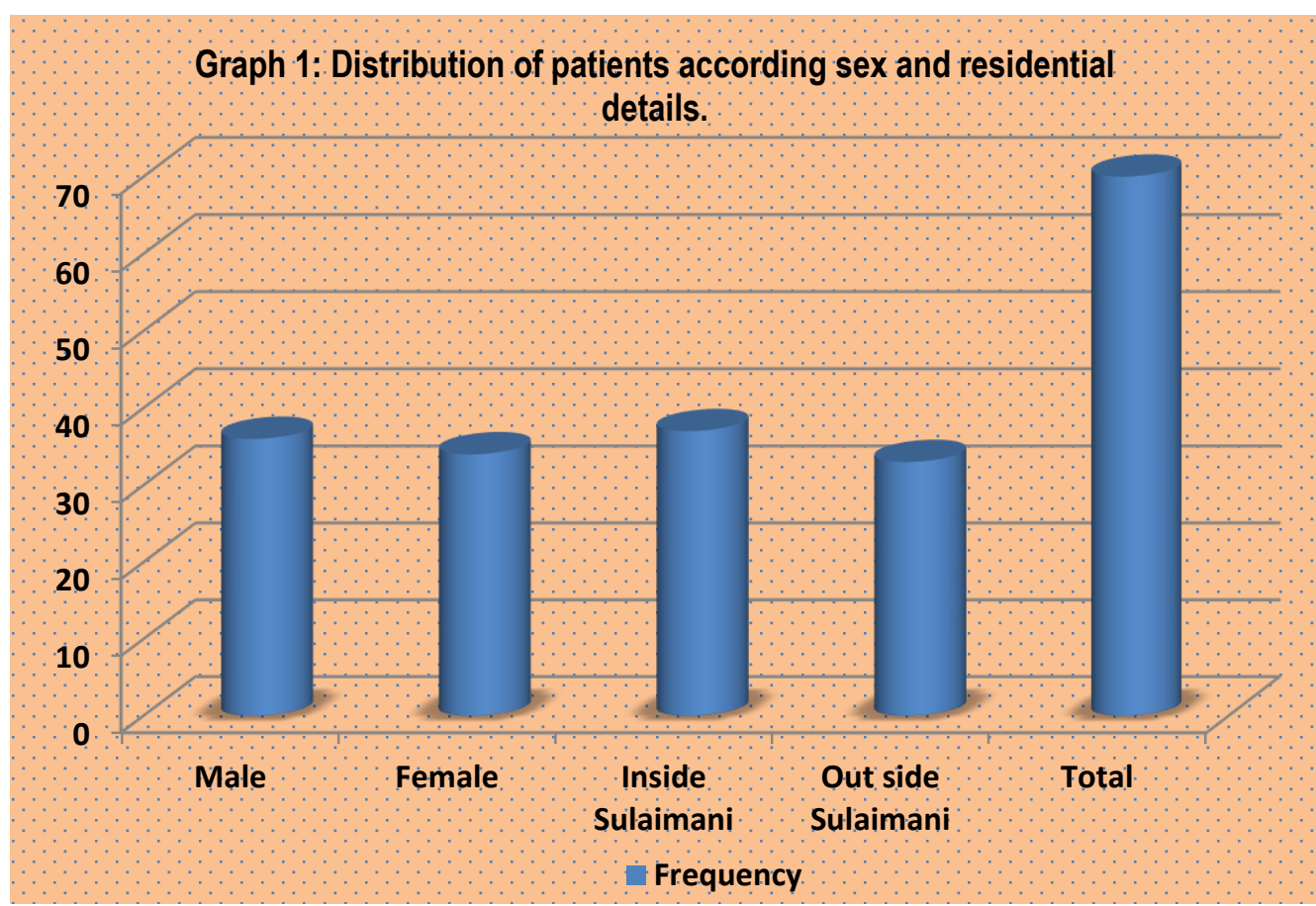

\section{RESULTS}

Graph 1 highlights the distribution of individuals on the basis of sex and residence distribution. $51.4 \%$ percent of the patients in the present study were males and $48.6 \%$ were females. Subjects were almost equally distributed to inside and outside Sulaimani city.

Table 1 highlights the comparative evaluation of the pre-surgical uncorrected and best corrected visual acuity between the amblyopic and non-amblyopic among the subjects. Statistically significant result was obtained while comparing the amblyopic and non-amblyopic eye in uncorrected visual acuity. Also on comparing amblyopic and non-amblyopic eye for best corrected visual acuity, statistically significant results were obtained. Table 2 shows uncorrected and best corrected visual acuity before and after operation among the study patients. In patients with uncorrected visual acuity, significant results were obtained while comparing follow-up at all the post-surgical time intervals. Whereas in patients with best corrected visual acuity, significant results were obtained at 1 month follow-up time. 
Fig 1. Pie chart shows flap conidtion after LASIK
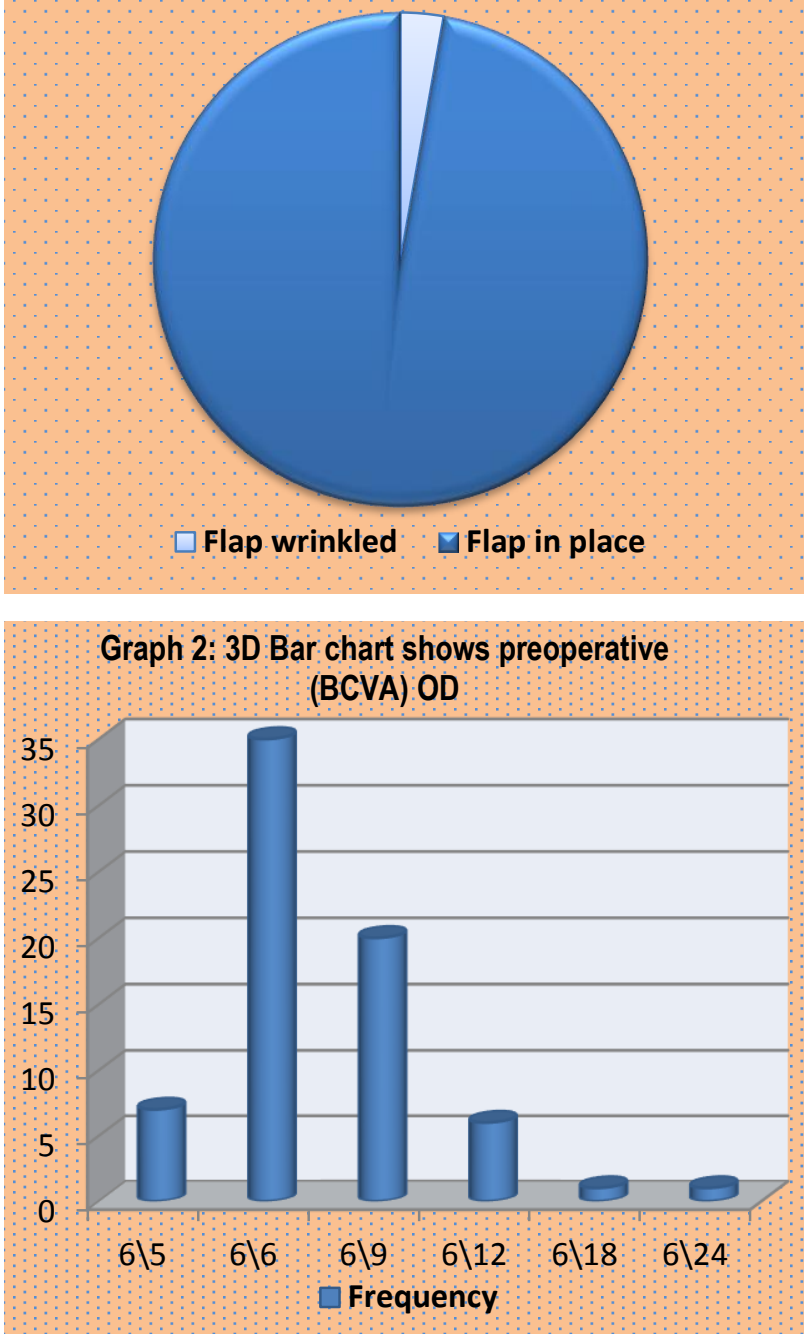

\section{DISCUSSION}

Reduction of best-corrected visual acuity (BCVA) in the absence of any other cause is referred to as amblyopia. Refractive amblyopia is successfully treated in children with appropriate correction of refractive errors with contemporary occlusion. 6,7 In the adult population, such treatment proves to be less efficient. However, some authors report encouraging data. ${ }^{8}$ Although used in paediatric population, Excimer laser refractive surgery in patients with anisometropic amblyopia remains controversial.9- 16 In the literature we found only three reports concerning visual outcome in amblyopic adults after refractive surgery and they exhibit a small number of eyes. Visual acuity in amblyopic adults after refractive procedure has been reported by Dedhia and Behl, Barequet et al, and Sakatani et al, but their reports include a small number of eyes with high variability of amblyopia. ${ }^{17-19}$ In adult population, due to the higher incidence of anisometropic amblyopia, the improvement of visual outcome in such patients should be seen as a social goal. ${ }^{20}$ This study was conducted to evaluate the visual outcome of patients with anisometropic amblyopia after LASIK surgery.

In the present study, 68 eyes were examined in adult population with refractive or anisometropic amblyopia. The most important data obtained in the present study are related to the group of patients with anisometropia. More than $80 \%$ of the eyes improved BCVA, out of which more than $15 \%$ remained unvaried, and none lost lines of preoperative BCVA. While making assessment, no
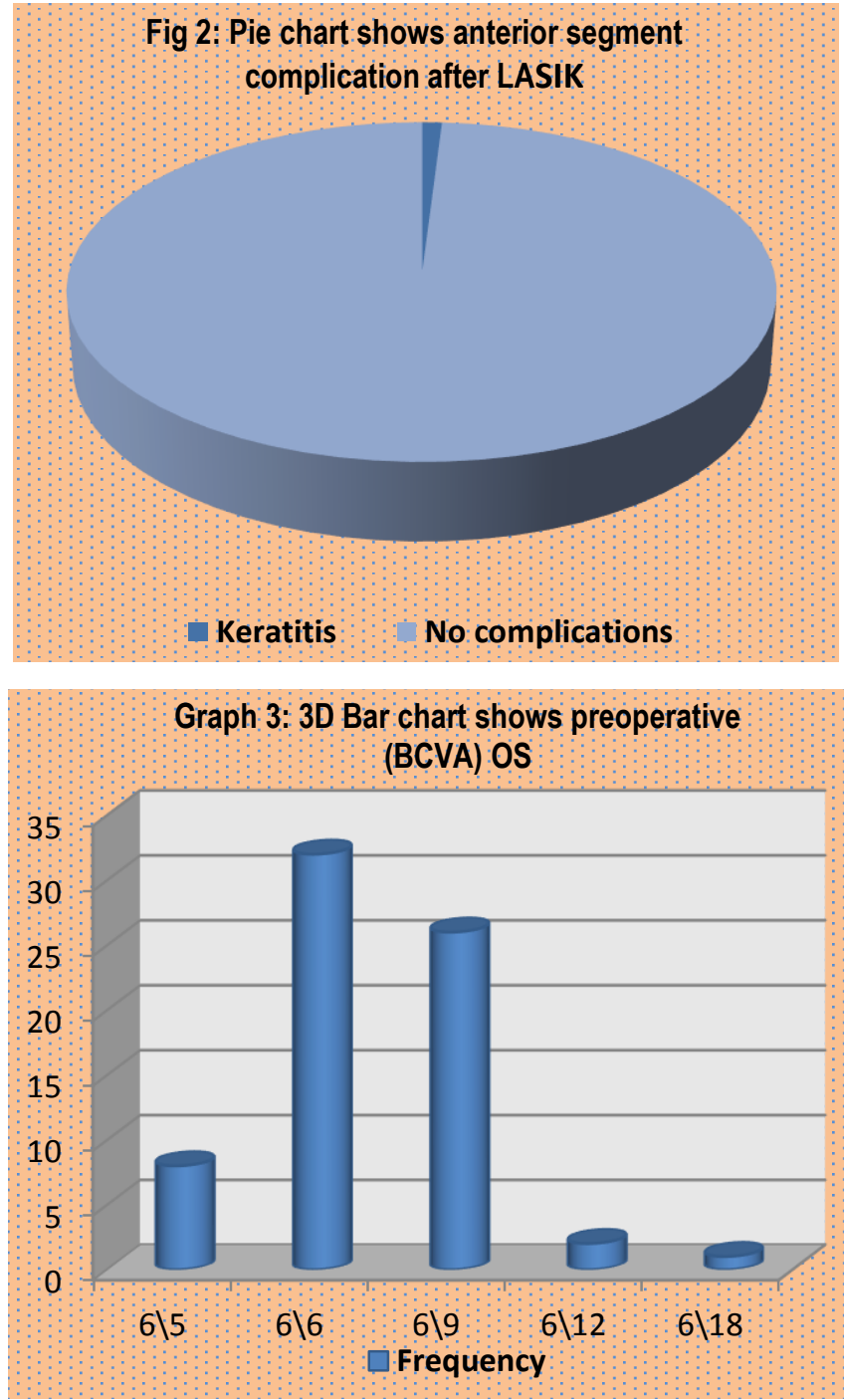

clinically significant haze was observed. When compared between dioptres of anisometropia and visual improvement, significant correlation between diopters of anisometropia and visual improvement was detected $(p<0.01)$. High visual recovery in eyes with anisometropic amblyopia is caused by high dioptric differences. Excimer laser refractive surgery appears to be a safe and effective procedure in the treatment of ametropic and anisometropic amblyopia in adults. Expectation of adult patients with anisometropic and refractive amblyopia benefit from refractive treatment and a good visual outcome are demonstrated by the present study. It is important that eye patient with anisometropic amblyopia can be expected with improvement of optical quality of the eye. Roszkowska et al evaluated the visual and refractive outcomes in adult patients with refractive and anisometropic amblyopia treated with photorefractive keratectomy. They analyzed 50 consecutive patients with amblyopia treated with photorefractive keratectomy and from the results, concluded that excimer laser refractive surgery might be a safe and efficient procedure in the treatment of ametropic and anisometropic amblyopia in adults. ${ }^{21}$ Astle et al assessed the refractive, visual acuity and binocular results of LASEK for anisomyopia, anisohyperopia, and anisoastigmatia in children. They retrospectively reviewed over 50 children with anisometropia who underwent LASEK for the correction of refractive difference between eyes. From the results, they concluded that LASEK is an effective surgical alternative for improving the visual acuity in 
anisometropic children in which conventional methods of treatment are not possible.22 Steele et al analyzed the prognosis of anisometropic amblyopia after treatment with spectacles alone. They reviewed the records of 28 patients who were successfully treated for anisometropic amblyopia with glasses alone. From the results, they concluded that treatment of anisometropic amblyopia with spectacles alone can be considered under the category of successful treatment option. ${ }^{23}$ Rajavi et al evaluated the long-term visual acuity (VA) outcome after congenital cataract surgery at a tertiary referral centre from 2004 to 2014. From the results, they concluded that rate of amblyopia can be reduced by early detection through screening. ${ }^{24}$ Tian et al conducted a systemic review of the past literature to evaluate and compare the various visual function parameters in the treatment of refractive amblyopic children. From the results, they concluded that the entire patient study groups showed certain advantages in treating refractive amblyopia in children. ${ }^{25}$ Autrata et al evaluated the the visual and refractive results of LASEK and anterior chamber phakic intraocular lens ( $\mathrm{plOL}$ ) implantation performed for high myopic anisometropia with amblyopia and contact lens intolerance in children compared with conventional treatment by contact lenses. From the results, they concluded that in children who receive permanent surgical correction of anisometropia have better outcomes in terms of visual acuity and binocular vision. ${ }^{26}$

\section{CONCLUSION}

From the above results, it can be concluded that in adults, for the treatment of ametropic and anisometropic amblyopia excimer laser refractive surgery appears to be a safe and efficient procedure. Further studies with longer time follow-up recommended to determine the final surgical and visual outcome.

\section{ACKNOWLEDGEMENT: Thanks to SOMA centre.}

\section{REFERENCES}

1. Steele AL, Bradfield YS, Kushner BJ, France TD, Struck MC, Gangnon RE: Successful treatment of anisometropic amblyopia with spectacles alone. J AAPOS 2006; 10: 37-43.

2. Cobb CJ, Russell K, Cox A, MacEwen CJ: Factors influencing visual outcome in anisometropicamblyopes. $\mathrm{Br} \mathrm{J}$ Ophthalmol 2002; 86: $1278-1281$.

3. France LW: Evidence-based guidelines for amblyogenic risk factors. AmOrthopt J 2006; 56: 7-14.

4. Chua BE, Johnson K, Martin F: A retrospective review of the associations between amblyopia type, patient age, treatment compliance, and referral patterns. ClinExpOphthalmol 2004; 32: 175179.

5. Freeman MI. Spectacles vs contact lenses in the correction of unilateral axial myopia. Arch Ophthalmol 1992; 110:180.

6. Krumholtz I, Fitzgerald D. Efficacy of treatment modalities in refractive amblyopia. J Am OptomAssoc 1999; 70: 399-404 .

7. Spiritus M. Detection, prevention and rehabilitation of amblyopia. CurrOpinOphthalmol 1997; 8: 11-6.

8. Saulles $H$. Treatment of refractive amblyopia in adults. J Am OptomSci 1987; 58: 959-60.

9. Nano HD, Muzzin S, Irigaray F. Excimer laser PRK in pediatric patients. J Cataract Ref Surg 1997; 23: 736-9.

10. Aliò JL, Artola A, Claramonte P, Ayala MJ, Chipont E. P h o t 0 refractive keratectomy for pediatric myopic anis $0 \mathrm{~m} \mathrm{e} \mathrm{t}$ ropia. $\mathrm{J}$ Cataract Refract Surg 1998; 24: 327-30.
11. Nucci $P$, Drack AV. Refractive surgery for unilateral high myopia in children. J AAPOS 2001; 5: 348-51.

12. Nassaralla BR, Nassaralla JJ Jr. Laser in situ keratomileus i $s$ in children 8 to 15 years old. J Refract Surg 2001;17:519 -24

13. Rashad KM. Laser in situ keratomileusis for myopic anis o $\mathrm{m} \mathrm{e} \mathrm{t}$ ropia in children. J Refract Surg 1999; 15: 429-35.

14. Singh D. Photorefractive keratectomy in pediatric patients. J Cataract Refract Surg 1995; 21: 630-2.

15. Paysse EA, Hamill MB, Hussein MA, Koch DD. Photo refractive keratectomy for pediatric anisometro $\mathrm{p} i \mathrm{a}$ : safety and impact on refractive erro $r$, visual acuity and $\mathrm{s} t \mathrm{e}$ reopsis. Am $\mathrm{J}$ Ophthalmol 2004; 138: 70-8.

16. Autrata R, Rehurek J. Laser-assisted subepithelial keratectomy and photorefractive keratectomy versus conventional treatment of myopic anisometropic amblyopia in children. J Cataract Refract Surg. 2004; 30: 74-8 4 .

17. Dedhia NC, Behl S. Laser in situ keratomileusis for anis o $\mathrm{m} \mathrm{e} \mathrm{t}$ ropic amblyopia. J Refract Surg 2000; 16: 264-7.

18. B a requet IS, Wygnanski-Jaffe $T$, Hirsh A. Laser in situ keratomileusis improves visual acuity in some adult eyes with amblyopia. J Refract Surg 2004; 20: 25-8.

19. Sakatani K, Jabbur NS, O'Brien TP. Improvement in bestco rrected visual acuity in amblyopic adult eyes after laser in situ keratomileusis. J Cataract Refract Surg 2004; 30: 2517-21.

20. Attebo K, Mitchell P, Cumming R, Smith W, Jolly N, Sparkes R. Prevalence and causes of amblyopia in an adult population. Ophthalmology 1998; 105: 154-9.

21. Roszkowska AM, Biondi S, Chisari G, Messina A, Ferreri FM, Meduri A. Visual outcome after excimer laser refractive surgery in adult patients with amblyopia. Eur J Ophthalmol. 2006 MarApr;16(2):214-8.

22. Astle WF, Rahmat J, Ingram AD, Huang PT. Laser-assisted subepithelial keratectomy for anisometropic amblyopia in children: Outcomes at 1 year. J Cataract Refract Surg 2007; 33:2028-2034.

23. Steele AL, Bradfield YS, Kushner BJ, France TD, Struck MC, Gangnon RE. Successful treatment of anisometropic amblyopia with spectacles alone.J AAPOS. 2006 Feb;10(1):37-43.

24. Rajavi Z, Mokhtari S, Sabbaghi H, Yaseri M. Long-term visual outcome of congenital cataract at a Tertiary Referral Center from 2004 to 2014. J CurrOphthalmol. 2016 Jan 13;27(3-4):103-9.

25. Tian $C$, Peng $X$, Fan Z, Yin Z. Corneal refractive surgery and phakic intraocular lens for treatment of amblyopia caused by high myopia or anisometropia in children. Chin Med $\mathrm{J}$ (Engl). 2014;127(11):2167-72.

26. Autrata R, Krejčírová I, Griščíková L, Doležel Z. Refractive Surgery in Children with Myopic Anisometropia and Amblyopia in Comparison with Conventional Treatment by Contact Lenses. CeskSlovOftalmol. 2016 Spring;72(2):12-9.

\section{Source of Support: Nil. Conflict of Interest: None Declared.}

Copyright: (c) the author(s) and publisher. IJMRP is an official publication of Ibn Sina Academy of Medieval Medicine \& Sciences, registered in 2001 under Indian Trusts Act, 1882.

This is an open access article distributed under the terms of the Creative Commons Attribution Non-commercial License, which permits unrestricted non-commercial use, distribution, and reproduction in any medium, provided the original work is properly cited.

Cite this article as: Diar Hadi Saeed, Ali Abdullah Taqi. Assessment of Visual Outcome of Anisometropic Amblyopia after LASIK Treatment. Int J Med Res Prof. 2016; 2(4):139-42. 